\title{
In Memoriam \\ Eliezer Dekel (1948-2020)
}

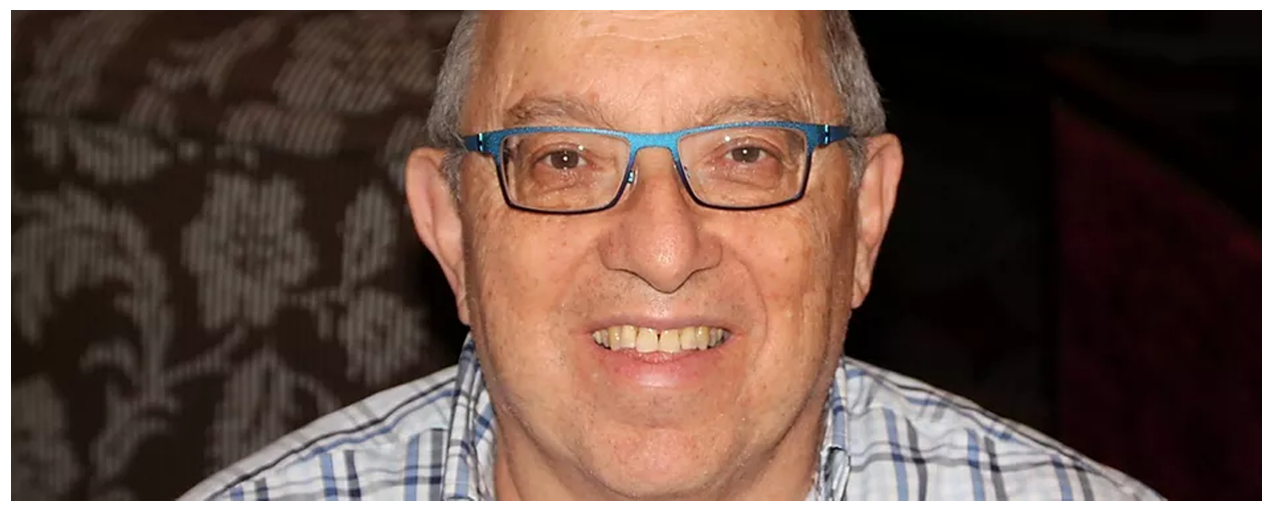

We are deeply saddened to announce that one of our most productive Associate Editors, Dr. Eliezer Dekel, passed away on February 18, 2020. Dr. Dekel provided admirable service to ACM Computing Surveys from 2013 to the time of his passing. Our heart felt condolences go out to Dr. Dekel's family. The following is reproduced from Dr. Dekel's Web site https://www.eliezerdekel.com with the permission of his family.

An industry leader, researcher, scientist, professor, and academic, Eliezer's contributions to the field of computer science are countless. He was a tireless and prolific innovator. A visionary in his own right, he foresaw and contributed to many of the technological breakthroughs of our times. A man with vast knowledge in many areas of life, he shared this and his skills with others as a teacher and a manager. He had an uncanny knack for human relations and a relaxed and positive demeanor.

A man of fierce integrity, Eliezer was gentle and humorous. He was also bold, fearless, and opinionated. Eliezer Dekel was a rare combination of a brilliant mind and a kind heart-a man who loved people, his family, and his work.

Eliezer was born in Tel Aviv, Israel, and moved to the United States to pursue computer science studies at the University of Minnesota. After receiving his Ph.D., he became a professor and a faculty member at the University of Texas at Dallas, where he was an advisor for doctoral candidates.

In 1992, Eliezer and his family moved to Israel, where he joined IBM Research. At IBM, Eliezer was a senior manager and technical expert, building powerful teams, and leading them toward award-winning technical innovations that greatly impacted the industry. In addition to working globally across IBM, he worked and collaborated with many organizations the world over, including various academic institutions, such as Cornell, the Hebrew University of Jerusalem, the Technion, the Sapienza University of Rome, and more.

Eliezer also continued his academic path, serving as an adjunct professor at the Technion, and as a visiting researcher at the Swedish Institute of Computer Science, while working as an editor for many journals and publications such as ACM, IEEE, and European Alliance for Innovation (EAI).

(c) 2020 Copyright held by the owner/author(s). 0360-0300/2020/04-ART23e

https://doi.org/10.1145/3389414 
After retiring from IBM, Eliezer began a new chapter in his career as a chief technical officer in Huawei, where he worked until eventually retiring in 2019. At Huawei he spearheaded efforts in new technology and collaborative projects.

Throughout his professional career, Eliezer was also very active in the community, volunteering in the preservation efforts of the Carmel mountain in Haifa, as well as serving as the head of the Parent Teacher Association of the Reali Hebrew School in Haifa.

He had a brilliant mind and a sharp wit; he was a kind and wise man who was generous with both qualities. Eliezer will be greatly missed, as he was an inspiration in his life and in his work.

Sartaj Sahni

Albert Y. Zomaya 